\title{
Effects of Recreational Activity on Leisure Barriers between Students
}

\section{Yener Aksoy ${ }^{1 \otimes}$ \\ Oguzhan Arslan ${ }^{2}$}

Yasar Dogu Sport Sciences Faculty, Samsun, Turkey.

Email:yeneraksoygsim@gmail.com

${ }^{2}$ Selcuk University Health Sciences Institute, Konya, Turkey.

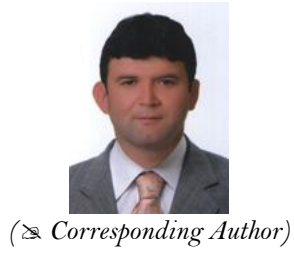

\section{Abstract}

Recreation, which means relaxing and pleasant activities that people do voluntarily in their free time, is a concept that provides the physical and psychological renewal of individuals. The study was conducted on a total of 497 students, 248 men participating in recreational sports activities and 249 men who did not participate in any recreational activities. For this purpose "Leisure Constraints Scale", which was developed by Alexandris and Carroll (1997) and was conducted in the study of the validity and reliability for Turkish Society by Karaküçük and Gürbüz (2007) was used. Statistical analysis of the study was performed by using SPSS 22,0 package program. The normality hypothesis of the data was analyzed by Kolmogorov-Smirnov test. Since all variables showed normal distribution, parametric tests were applied to the independent variables related to the sub-problems and the leisure time scale subscales. Independent $t$ test was used for paired comparisons and Pearson correlation was used for the relationship between variables. Statistical results were evaluated at $95 \%$ confidence interval and $\mathrm{p}<0.05$ significance level. As a result, statistically significant differences were found between the students participating in sportive recreation activity in the field and those who did not participate in any recreational activity in terms of leisure time barriers in terms of Individual Psychology, Social Environment, Service and Transportation, Time, Lack of Friends and Lack of Interest. $(\mathrm{p}<0,05)$.
Citation | Yener Aksoy; Oguzhan Arslan (2019). Effects of Recreational Activity on Leisure Barriers between Students. Asian Journal of Education and Training, 5(4): 569-574.

History:

Received: 3 September 2019

Revised: 7 October 2019

Accepted: 11 November 2019

Published: 13 December 2019

Licensed: This work is licensed under a Creative Commons Attribution 3.0 License (cc)

Publisher: Asian Online Journal Publishing Group
Acknowledgement: Both authors contributed to the conception and design of the study.

Funding: This study received no specific financial support.

Competing Interests: The authors declare that they have no conflict of interests.

Transparency: The authors confirm that the manuscript is an honest, Transparency: The authors confirm that the manuscript is an honest,
accurate, and transparent account of the study was reported; that no vital accurate, and transparent account of the study was reported; that no vital
features of the study have been omitted; and that any discrepancies from the study as planned have been explained.

Ethical: This study follows all ethical practices during writing.

\section{Contents}

1. Introduction 


\section{Contribution of this paper to the literature}

In this study it is aimed to compare the attitudes and behaviors of the students who do sports for recreative purposes on carpet pitches in Ankara and the others who don't participate in recreational activities, chosen randomly, towards free time barriers.

\section{Introduction}

Sport has been not only an important part of the development of societies since the early ages, but also it has been an activity in which many people from around the world participate in their free time. Physical activity and sport activities are very important for modern societies.

Nowadays, sport has become a part of human life and it is impossible to think doing sports only as a physical gain for individuals. We need to consider the physical, psychological and social benefits of sports to individuals as a whole (Yarımkaya et al., 2014).

While physical activity has been a condition for human beings to continue their lives and transmit their genes to the next generations for centuries, nowadays, due to technological development, the importance of physical activities in both working life and transportation and leisure activities has diminished. This situation makes our lives easier in one way and it affects the other side quite negatively. Therefore, using technological advances until the human loses his mobility can have a direct negative impact on human health (Alpözgen and Ozdinçer, 2016).

So exercise for a healthy life should be part of people's daily life and lifestyle. Exercise and physical activity help to achieve better physical and mental health, improve quality of life, and also this prolongs lives. People are now intensely involved in many sports and leisure activities.

This interest in sports and entertainment has increased and continues to increase in the importance they attach to their health, emotional, physical and psychological moods by the influence of a growing trend in the early 20th century (Horner and Swarbrooke, 2005).

People have physical and emotional needs as well as social needs. Nowadays, in order to meet these needs, it is necessary to direct people to sports, to help them to develop their skills through sports and to enable them to do sports in order to stay healthy (Hacıcaferoğlu et al., 2012).

Getting people used to sports, helping them to develop their skills and the necessity of doing sports in order to remain healthy are now known by all segments of society.

In order to get away from the economic problems and complex city life they live in today's living conditions and to relieve themselves from mental and physical fatigue people tend to a number of sportive, social and artistic recreational activities that will relax them.

Recreation is an activity that attracts a wide range of sports activities and attracts a wide audience. However, in order to be seen as a recreational phenomenon, participation in sport activities must be realized in leisure time with the purposes of entertainment, physical activity and play. (Sevil et al., 2012).

According to these explanations, it is seen that the sport is used as a recreational phenomenon when it is carried out in order to relax, have fun, socialize and improve physical health alongside the amateur spirit.

Recreational activities have been an important part of life. Recreational activities are seen as organizations that increase the quality of life and give meaning to life.

In this sense, people all over the world participate in recreational activities due to their physical, spiritual and social benefits (Sevil et al., 2012).

These recreational activities can reduce the stress that may be caused by adverse environmental conditions and also make a positive contribution to the mental and physical health of the individual and the development of his social life (Ozer and Cavuşoğlu, 2014).

Recreational activities that people participate in their spare time seem to be very beneficial for their health ( both mental and physical). Variables depending on the socio-economic structure of individuals are an important factor affecting recreational tendencies and demands. It is known that knowing what factors affect people's attitudes, perception and preferences is an important condition for ensuring the quality of recreation. (Dorwart et al., 2004).

The leisure activities are very different depending on the scope of the activities and the areas in which they are performed. Which of these activities will be preferred depends on the structure of the individual, the education, the gender, the possibilities and of course the characteristics (Pulur, 2003).

In many studies conducted in different fields, it has been observed that recreational activities add a lot of positive effects to social health. Despite these positive contributions of participation in recreational activities, it has been observed that individuals do not participate in such activities which are very important for them due to various reasons or they cannot participate due to various obstacles. The term "obstacle" refers to the reasons in the leisure literature that prevent or restrict an individual's participation in recreational activities in his spare time (Karaküçük and Gürbüz, 2007). Studies also reveal that people do not engage in such activities that are important for them for various reasons or that they are prevented for various reasons (Alexandris and Carroll, 1997; Kyle and Mowen, 2003).

There is a connection between the two, if we consider people and leisure time. Therefore, reasons such as insufficient housing and estrangement from nature may constitute some obstacles to participation in leisure activities, as well as the pace of city life and technology, crowd, etc. are just a few of the reasons that may impede the participation in recreational activities (Leighfield, 2001). These types of obstacles cause people not to throw in excess energy and reveal various abilities. In this environment, one feels himself under constant pressure and stress, especially among the young; the need for further action, innovation and change leads to various hardship and problems (Karaküçük, 2005).

Today, football is the most popular branch of sports. The interest of this sport, in which men especially show great interest, has also increased in women recently. In addition to football's power improving the physical and physiological qualifications, it is also important in terms of socialization. In particular, men who are interested in football but cannot devote time for themselves due to daytime work rush go to play football on the carpet pitch in 
order to do sports and spend efficient time with their friends. The aim is to participate in a sporting event and have fun.

The aim of this study is to investigate the relationship between the attitudes towards leisure time activities and the factors preventing leisure activities between the participants who are active in recreation activities and participate in this sport and who do not participate in any sport activity in their free time.

\section{Material Method}

\subsection{Leisure Barriers Scale}

The study was conducted on a total of 497 (331 man who was in university and 166 man who was in high school students), 248 men participating in recreational sports activities and 249 men who did not participate in any recreational recreational activities.

The "Leisure Barriers" scale was used to compare the attitudes and behaviors of the two different groups in relation to leisure time barriers. The data collection tool used in the study consists of two parts. In the first part, the democratic information of the participants was used and in the second part, "Leisure Barriers" scale consisting of 6 sub-dimensions and 27 items developed by Alexandris and Carroll (1997) was used. The validity and reliability study of the scale for the Turkish Community was conducted by Karaküçük and Gürbüz (2007). Cronbach "es alpha internal consistency value is 0.864 .

\subsection{Analysis of Data}

Statistical analysis of the study was performed by using SPSS 22.0 package program. The normality assumption of the data was examined by Kolmogorov-Smirnov test. Since all variables showed normal distribution, parametric tests were applied to the independent variables related to the sub-problems and the leisure time scale subscales. Independent $t$ test was used for paired comparisons and Pearson correlation was used for the relationship between variables. Statistical results were evaluated at $95 \%$ confidence interval and $\mathrm{p}<0.05$ significance level.

\section{Results}

In this part of the study, the data obtained from the researches are presented in tables by making comparisons between the groups.

\begin{tabular}{|c|c|c|c|c|}
\hline Sub dimensions & Sportive background & $\mathbf{n}$ & Mean sd & $\mathbf{P}$ \\
\hline Individual psychology & $\begin{array}{c}\text { Active } \\
\text { Inactive } \\
\end{array}$ & $\begin{array}{l}248 \\
249 \\
\end{array}$ & $\begin{array}{l}9.10 \pm 3.22 \\
8.04 \pm 3.31 \\
\end{array}$ & $<0.001$ \\
\hline Social environment & $\begin{array}{c}\text { Active } \\
\text { Inactive }\end{array}$ & $\begin{array}{l}248 \\
249 \\
\end{array}$ & $\begin{array}{l}12.24 \pm 3.79 \\
10.96 \pm 4.35\end{array}$ & $<0.001$ \\
\hline Service and transportation & $\begin{array}{l}\text { Active } \\
\text { Inactive }\end{array}$ & $\begin{array}{l}248 \\
249\end{array}$ & $\begin{array}{l}19.70 \pm 5.48 \\
17.87 \pm 6.35\end{array}$ & $<0.001$ \\
\hline Lack of friends & $\begin{array}{l}\text { Active } \\
\text { Inactive }\end{array}$ & $\begin{array}{l}248 \\
249\end{array}$ & $\begin{array}{l}7.02 \pm 2.17 \\
6.36 \pm 2.59\end{array}$ & .002 \\
\hline Time & $\begin{array}{c}\text { Active } \\
\text { Inactive }\end{array}$ & $\begin{array}{l}248 \\
249\end{array}$ & $\begin{array}{l}9.89 \pm 2.90 \\
9.22 \pm 3.51\end{array}$ & .020 \\
\hline Lack of interest & $\begin{array}{c}\text { Active } \\
\text { Inactive }\end{array}$ & $\begin{array}{l}248 \\
249\end{array}$ & $\begin{array}{l}7.16 \pm 2.30 \\
6.22 \pm 2.72\end{array}$ & $<0.001$ \\
\hline
\end{tabular}

\section{*P<0,05; N (497)}

According to the Table 1, when we examine the values of individual psychology, social environment, service and transportation, lack of friends, lack of interest and time sub-dimensions regarding active and inactive groups, a statistically significant difference was found between them. $(\mathrm{P}<0.05)$.

Table-2. Comparison of parameters for preventing participation in sportive recreational activities regarding educational status for all data.

\begin{tabular}{|c|c|c|c|c|}
\hline Sub dimensions & Educational status & $\mathbf{n}$ & Mean sd & $\mathbf{P}$ \\
\hline Individual psychology & $\begin{array}{c}\text { University } \\
\text { High School }\end{array}$ & $\begin{array}{l}331 \\
166\end{array}$ & $\begin{array}{l}9.43 \pm 3.21 \\
6.86 \pm 2.81\end{array}$ & $<0.001$ \\
\hline Social environment & $\begin{array}{c}\text { University } \\
\text { High School }\end{array}$ & $\begin{array}{l}331 \\
166\end{array}$ & $\begin{array}{c}12.56 \pm 3.71 \\
9.68 \pm 4.26\end{array}$ & $<0.001$ \\
\hline Service and transportation & $\begin{array}{c}\text { University } \\
\text { High School }\end{array}$ & $\begin{array}{l}331 \\
166\end{array}$ & $\begin{array}{l}20.39 \pm 5.31 \\
15.58 \pm 6.01\end{array}$ & $<0.001$ \\
\hline Lack of friends & $\begin{array}{l}\text { University } \\
\text { High School }\end{array}$ & $\begin{array}{l}331 \\
166\end{array}$ & $\begin{array}{l}7.22 \pm 2.31 \\
5.64 \pm 2.26\end{array}$ & $<0.001$ \\
\hline Time & $\begin{array}{l}\text { University } \\
\text { High School }\end{array}$ & $\begin{array}{l}331 \\
166\end{array}$ & $\begin{array}{c}10.34 \pm 2.82 \\
7.98 \pm 3.43\end{array}$ & $<0.001$ \\
\hline Lack of interest & $\begin{array}{c}\text { University } \\
\text { High School }\end{array}$ & $\begin{array}{l}331 \\
166\end{array}$ & $\begin{array}{l}7.32 \pm 2.50 \\
5.42 \pm 2.19\end{array}$ & $<0.001$ \\
\hline
\end{tabular}

According to Table 2, when the values of the individual psychology, social environment, service and transportation, lack of friends, lack of time and interest sub-dimensions are examined, it is seen that there is a statistically significant difference between the educational levels. 


\begin{tabular}{|c|c|c|c|c|}
\hline Sub dimensions & Occupation & $\bar{n}$ & Mean sd & $\mathbf{P}$ \\
\hline Individual psychology & $\begin{array}{c}\text { Unemployed } \\
\text { Employed }\end{array}$ & $\begin{array}{l}356 \\
141\end{array}$ & $\begin{array}{l}8.90 \pm 3.44 \\
7.60 \pm 2.67\end{array}$ & $<0.001$ \\
\hline Social environment & $\begin{array}{c}\text { Unemployed } \\
\text { Employed }\end{array}$ & $\begin{array}{l}356 \\
141\end{array}$ & $\begin{array}{l}11.95 \pm 3.99 \\
10.70 \pm 4.31\end{array}$ & .002 \\
\hline Service and transportation & $\begin{array}{c}\text { Unemployed } \\
\text { Employed }\end{array}$ & $\begin{array}{l}356 \\
141\end{array}$ & $\begin{array}{l}19.28 \pm 5.88 \\
17.53 \pm 6.23\end{array}$ & .004 \\
\hline Lack of friends & $\begin{array}{l}\text { Unemployed } \\
\text { Employed }\end{array}$ & $\begin{array}{l}356 \\
141\end{array}$ & $\begin{array}{l}6.97 \pm 2.42 \\
6.04 \pm 2.29\end{array}$ & $<0.001$ \\
\hline Time & $\begin{array}{c}\text { Unemployed } \\
\text { Employed }\end{array}$ & $\begin{array}{l}356 \\
141\end{array}$ & $\begin{array}{l}9.86 \pm 3.14 \\
8.71 \pm 3.34\end{array}$ & $<0.001$ \\
\hline Lack of interest & $\begin{array}{c}\text { Unemployed } \\
\text { Employed }\end{array}$ & $\begin{array}{l}356 \\
141\end{array}$ & $\begin{array}{l}6.85 \pm 2.57 \\
6.29 \pm 2.47\end{array}$ & .030 \\
\hline
\end{tabular}

\section{*P<0,05; $\mathrm{N}(497)$}

Employed

According to Table 3; When we examine the values of individual psychology, social environment, service and transportation, lack of friends, lack of interest and time sub-dimensions related to occupations, a statistically significant difference was found between unemployed and employed. $(\mathrm{P}<0.05)$.

\section{Discussion and Conclusion}

Leisure time is the time helps individuals to integrate, interact and cooperate in cultural, social, psychological and professional life with other people that they willingly use for resting, having fun and social and personal success in the remaining time of work and other duties. In another aspect, it is an education that helps the individual to express himself / herself creatively and to gain ideas for the leisure activity that improves his / her personality (Karakullukçu, 2009). Leisure time is free time. Nowadays, what people engage in their spare time is as important as the profession or education they have, and at the same time it is expected to be parallel with the ones that they have. People save themselves from the wheels and systematic of the mechanized world and try to breath and cope with the difficulties of working life thanks to free time. Although it has been determined that participation in recreational activities has a very important place in human life, it shows that many students do not participate in recreational physical activity either at all or at a sufficient level.

In our study, what kind of difficulties are faced by the students who are doing sports on the carpet pitch and who do not do any sport while evaluating the leisure time, or the factors that prevent them from using the leisure time efficiently were revealed by our research.

In the study conducted to investigate the leisure time barriers of students who do sports and who do not do sports in the carpet field in Ankara province, 249 sportive volunteer and 248 non-sportive volunteer students participated in our study. Leisure barriers according to the demographic variables of the participants were discussed with statistical findings.

Descriptive statistics regarding the importance level of the parameters that prevent students from participating in sportive recreational activities according to the state of doing sports in the carpet field and not doing any sport are as follows. The mean level of leisure time barriers of the "Individual Psychology" subscale was found to be X = $9.10 \pm 3.22$ in the sports participants and $\mathrm{X}=8.04 \pm 3.31$ in the non-sports participants. According to Crawford $e t$ al. (1991), individual's participation in leisure activities is hindered by individual (psychological attitudes, etc.), interpersonal (spouses, friends, etc.) and structural (transportation, facilities, etc.). It is obvious that sport contributes to physical and physiological development as well as psychological development. This difference may be caused by students inclination to engage in sports in order to stay away from the stress of work and the hustle and bustle of life.

The average of the level of importance of leisure barriers related to the social environment"sub-dimension was $\mathrm{X}=12.24 \pm 3.79$ for those who do sports, and for those who do not do sports $\mathrm{X}=10.96 \pm 4.35$ and it was found that there was a statistically significant difference between the values. Sport is one of the important facts that socialize people. Many people are aware of how strong the social aspect of sport is. In our study, the students who did football activity in the field were compared with those who did not do any sports. Since football is a team sport, it plays a role in the socialization of people. In particular, the most important recreational activity in which men participate with friends is carpet football. Therefore, since it is a popular activity with the group, it can be seen that there is a significant difference between those who do this sport and those who do not. It is seen that the mean value of leisure time barriers of the "Service and Transportation" sub-dimension is $\mathrm{X}=19.70 \pm 5.48$ for the sportsmen and $\mathrm{X}=17.87 \pm 6.35$ for the non-sportsmen. As it is known, carpet field is a private enterprise and service fee is paid for the activity. Establishing and operating a carpet field is a financially burdensome business and requires a license. This also has certain conditions by the municipalities. One of these is to make these facilities to the places that are far from the living areas rather than the city center, which will not disturb the lives of the students. For these reasons, those who want to do sports in the carpet field, both service and transportation costs have to pay. Therefore, it is natural that there is such a difference between those who do sports in the carpet field and those who do not. The mean level of leisure barriers for the "Lack of Friends" subscale was found to be $\mathrm{X}=$ $7.02 \pm 2.17$ in sportsmen and $\mathrm{X}=6.36 \pm 2.59$ in sportsmen, and statistically significant differences were found between them. As we mentioned above, football is a team sport and participating in this activity on the carpet pitch is a friend activity. This activity requires 6-7 people in a team. People need a companion to accompany their leisure time. This difference may be due to the fact that students who do not have any sports do not have enough friends or do not have enough friends who are interested in football. The mean of the leisure time barriers of the "time" subscale was found to be $\mathrm{X}=9.89 \pm 2.90$ for those who do sports, and $\mathrm{X}=9.22 \pm 3.51$ for those who do not perform sports. One of the most important problems of our time is shortness of time. The increasing importance of time has demonstrated the importance and effective use of time outside work, that is, leisure time. Every person has time for sports. If you don't have time to play, it means you're really busy. Such a difference may have occurred 
since there is no time for people to work out from their busy working tempo, wasted time in traffic, resting at home or wanting to spend at home with their family. Moreover, the fact that the participants spent their free time with different activities and social activities instead of sports might have made this difference meaningful. The mean of the level of importance of leisure barriers of the "Lack of Interest" subscale was found to be $\mathrm{X}=7.16 \pm 2.30$ in the sportsmen and $\mathrm{X}=9.22 \pm 3.51$ in the non-sportsmen, and statistically significant differences were found between them. People are social creatures and everyone has to deal with, love, do, watch and so has an activity of interest to him. Our study is on a special event on the carpet field. Although football is the most popular sport in the world, the variety of interests, the students who participated in our study may have spent their free time in different areas of interest, lack of skills or interest in sports may be effective in making a significant difference between those who do sports and those who do not. Differences were determined in terms of the importance of leisure time barriers in terms of human psychology, lack of knowledge and lack of partners.

These differences are due to the fact that the importance of participation of recreational sports teachers in recreational activities is lower than the level of importance of teachers who do not do sports and occasionally and regularly do sports (Ozsoy, 2018).

In his study, Sabanci stated that the average scores of the academicians' leisure time scale, individual psychology, lack of information, transportation problem and facility insufficiency did not differ significantly according to whether they were active in sports; the mean scores of the lack of time and interest and lack of friends subscales differ significantly in favor of academicians who did not actively engage in sports (Sabancl, 2016).

In a study conducted by Daminianidis (2007) on secondary and high school students in order to identify the perceived barriers to participation in extracurricular activities, it was found that the students who participated in sports activities had higher scores (Daminianidis, 2007). It supports our study in the studies in the literature. When the literature is examined, it is seen that individuals who engage in sports are more likely to experience leisure time barriers than those who do not.

Some researchers have emphasized that leisure education should be the main purpose of education. They equated leisure education with education for life. Therefore, the gains that education provides to the individual both in terms of level and theoretically have undoubtedly an effect on the evaluation of an individual's free time. In this respect, it is important to examine the effect of education awareness and level on individuals' leisure time (Karakullukçu, 2009).

Descriptive statistics related to the importance level of the parameters preventing the participation of students to sportive recreational activities according to their educational level (University graduate: 331, high school graduate: 166) are as follows. The average level of the importance of leisure time barriers of the "Individual Psychology" sub-dimension was found to be $\mathrm{X}=9.43 \pm 3.21$ in university graduates and $\mathrm{X}=6.86 \pm 2.81$ in high school graduates. The average level of the importance of leisure barriers of the "Social Environment" subdimension was found to be $\mathrm{X}=12.56 \pm 3.71$ in university graduates and $\mathrm{X}=9.68 \pm 4.26$ in high school graduates. The average level of leisure barriers for the service and transportation "sub-dimension was found to be $\mathrm{X}=20.39 \pm$ 5.31 for university graduates and $\mathrm{X}=15.58 \pm 6.01$ for high school graduates. The average level of leisure barriers for the "lack of friends" subscale was found to be $\mathrm{X}=7.22 \pm 2.31$ for university graduates and $\mathrm{X}=5.64 \pm 2.26$ for high school graduates. When the related values were examined, a statistically significant difference was found. It is seen that the mean of the leisure time barriers of the "time" sub-dimension is $\mathrm{X}=10.34 \pm 2.82$ for university graduates and $\mathrm{X}=7.98 \pm 3.43$ for high school graduates, and a statistically significant difference was found between the values. The mean level of leisure barriers for the lack of interest "subscale was found to be $\mathrm{X}=7.32 \pm$ 2.50 for university graduates and $\mathrm{X}=5.42 \pm 2.19$ for high school graduates, and statistically significant differences were found between them.

Temir and Gürbüz conducted a study titled Examining the Barriers to Participation in Recreational Activities conducted in 2012 and found a significant difference between leisure time participation in recreational activities and education levels. It is seen in a survey Öztürk made in 2013 that as the education levels of the employees in the industrial sector increased, participation in the recreational activities are more preferred and attended.

According to the results of the one-way analysis of variance about who participated in leisure activities, there was a significant difference between the scores of participants with high school degree and associate / undergraduate and master / doctorate educational background (Karakullukçu, 2009).

Karaküçük (2005) found that $46.4 \%$ of the teachers did not have any difficulty in evaluating their free time and $33.8 \%$ sometimes had difficulties. According to this result, it can be said that there is a relationship between the difficulty in evaluating leisure time and the education level of the individual (Karaküçük, 2005).

Güngörmüş (2007) stated that as the education level increases, individuals gain awareness of healthy life (Güngörmüş, 2007).

Education is of great importance for people to improve themselves in all areas of life. Educated people understand the importance and benefits of sports more easily and participate in physical activities in order to enjoy life and spend a healthy and peaceful life. People with adequate education are more aware of this situation than those with inadequate education. When the literature studies mentioned above are examined, it is in parallel with our research. That is to say, conscious individuals may have the possibility of facing such barriers as they are more aware of their leisure time and also have more participation in recreational activities thanks to their planning of leisure activities.

Descriptive statistics regarding the importance level of the parameters preventing the participation of students in sportive recreational activities according to their occupations (unemployed: 356, employed: 141) are as follows. The average of the level of importance of leisure time barriers of the "Individual Psychology" subscale was found to be $\mathrm{X}=8.90 \pm 3.44$ in unemployed and $\mathrm{X}=7.60 \pm 2.67$ in the employed. It is seen that the average level of importance of leisure time barriers related to the Social Environment sub-dimension is $\mathrm{X}=11.95 \pm 3.99$ in unemployed and $\mathrm{X}=10.70 \pm 4.31$ in employed and when the related values are examined, a statistically significant difference is found between them. The average level of the importance of leisure barriers for the "Service and Transportation" sub-dimension was found to be $\mathrm{X}=19.28 \pm 5.88$ in the unemployed and $\mathrm{X}=17.53 \pm 6.23$ in the employed. The average level of leisure barriers for the "lack of friends" subscale was found to be $\mathrm{X}=6.97 \pm 2.42$ in 
the unemployed and $\mathrm{X}=6.04 \pm 2.29$ in the employed, and a statistically significant difference was found between them. The average of leisure time barriers subscale was found to be $X=9.86 \pm 3.14$ for the unemployed and $X=$ $8.71 \pm 3.34$ for the employed, and a statistically significant difference was found between them. The average level of importance of leisure barriers related to the lack of interest subscale was found to be $\mathrm{X}=6.85 \pm 2.57$ in the unemployed and $\mathrm{X}=6.29 \pm 2.47$ in the employed and statistically significant differences were found between them. high.

Barros and Nahas (2001) stated that the rate of physical inactivity of industrial workers in Southern Brazil is

Although the working hours of the unemployed are more precise (morning and evening working hours), the working time of the employed is not clear. The more regular working hours of unemployed may allow for planned participation in physical activity.

As a result, it was seen that students who did not participate in any recreational activities had less difficulty in evaluating their free time than those who participated in a recreational activity. In other words, students who do not do any sport do not encounter the obstacles faced by students doing sport. In addition, it was concluded that the factors that prevented the study group from evaluating their free time differed according to some demographic variables.

According to the results of the research, the following suggestions are given in the light of this information:

- Carrying out activities to increase the knowledge of recreational activities in the community.

- Increasing the number of recreational areas and improving the conditions of use.

- Implementing educational-oriented projects that can lead individuals to recreational activities.

- Making plans for the evaluation of free time by the institutions aiming to increase the productivity of working individuals.

\section{References}

Alexandris, K. and B. Carroll, 1997. Demographic differences in the perception of constraints on recreational sport participation: Results from a study in Greece. Leisure Studies, 16(2): 107-125.Available at: https://doi.org/10.1080/026143697375449.

Alpözgen, A.Z. and A.R. Ozdinçer, 2016. Physical activity and protective effects HSP, 3(1): 66-72.

Barros, M.V. and M.V. Nahas, 2001. Health risk behaviors, health status self-assessment and stress perception among industrial workers. Public Health Magazine, 35(6): 554-563.

Crawford, D.W., E.L. Jackson and G. Godbey, 1991. A hierarchical model of leisure constraints. Leisure Sciences, 13(4): 309-320.Available at: https://doi.org/10.1080/01490409109513147.

Daminianidis, C., 2007. Perceived barriers to participation of students in recreational activities Livadia city schools in Greece inquiriesin sport and physical education, 5(3): 379-385.

Dorwart, C., Y. Leung and R. Moore, 2004. Managingvisitors' perceptions. Parks and Recreation 2004, 39(5): 24-31.

Güngörmüş, H.A., 2007. Factors driving individuals receiving services from private health sports centers to recreational exercise Gazi university institute of health sciences department department of physical education and sports, Phd Thesis Ankara.

Hacıcaferoğlu, S., C. Gündoğdu and B. Hacıcaferoğlu, 2012. Evaluation of university students' thought against sports facilities and their organizations (İnönü University). Journal of Sport and Performance Research, 3(1): 42-51.

Horner, S. and J. Swarbrooke, 2005. Leisure marketing: A global perspective (paperback). 1st Edn., Oxford: Elsevier ButterworthHeinemann.

Karaküçük, S., 2005. Recreation, concept, scope and a research. 5th Edn., Ankara: Gazi Bookstore.

Karaküçük, S. and B. Gürbüz, 2007. Rekreational and urbanization. Ankara: Gazi Bookstore.

Karakullukçu, Ö.F., 2009. Recreational habits of ministry of justice employees according to their educational levels. Master Thesis, Ankara.

Kyle, G. and A. Mowen, 2003. An examination of the relationship between leisure constraints, involvement and commitment. Proceedings of the 2003 Northeastern Recreation Research Symposium.

Leighfield, M., 2001. Information for leisure community (translated by Demiray U). Monthly Tourism and Culture Art Magazine, 1: 7-10.

Ozer, E.Z. and F. Cavuşoğlu, 2014. The impact of local activities on rural tourism as a recreational activity. International Journal of Science Culture and Sport, 1(6): 191-191.Available at: https://doi.org/10.14486/ijscs 191.

Ozsoy, O., 2018. Investigation of leisure barriers of teachers in physical education, music and visual arts (the case of Sincan-Ankara). Master Thesis, Bartın.

Pulur, A., 2003. Investigation of sporting tendencies of academic staff and administrative staff in the university (the case of Kırıkkale). Congress of Social Areas in Physical Education and Sports. Ankara. pp: 10-11.

Sabanc1, G., 2016. Determination of factors preeventing teachers participation in recreational activities. Selçuk University Institute of Health Sciences Department of Physical Education and Sports, Phd Thesis Konya.

Sevil, T., K.Y. Şimşek, H. Katırcı, O. Çelik, M.A. Çeliksoy and S. Kocaekşi, 2012. Leisure and recreation management. 1st Edn.: Anadolu University. pp: 6-8.

Yarımkaya, E., M. Akandere and G. Baştuğ, 2014. Effect of self-confidence levels of 1214 years old students on their serving aiılity in volleyball. Niğde University Journal of Physical Education and Sport Sciences, 8(2): 242-250. 